\title{
About a Series of Late Medieval Moroccan Bindings
}

\begin{abstract}
The history of Islamic bindings is hampered by the lack of evidence about the date and place of production of the bindings. The library of the Saadian sultans of Morocco provides at least some clues about the local production in the fifteenth and sixteenth centuries, before the introduction of the plate stamping that local binders borrowed from Ottoman sources. As the library was captured by Spain in 1612, many bindings are still in the condition they were in at that date. This article focuses on manuscripts transcribed in Morocco during the fifteenth and sixteenth centuries and intends to define a type of bindings that seems to have been very successful at that moment.
\end{abstract}

\section{Introduction}

The culture of Saadian Morocco is of particular interest as it was a time of changes. Books were also involved. Their bindings bear witness to the shift in tastes but also in techniques that started during the sixteenth century. Slightly later, in the seventeenth century, al-Sufyānī wrote a treatise on bookbinding in which he described three kinds of bindings produced in Morocco in his time. ${ }^{1}$ According to Prosper Ricard, who edited this text, these three kinds of bindings were produced from al-Sufyānī's days until the nineteenth century. They are the Oriental type; the 'Hispano-Moorish' one and one with an infrequent decoration, used above all in the eighteenth century. ${ }^{2}$ We can conclude that there were two clearly different types of binding decorations in Morocco, one being usually defined as 'Maghrebi', with specific aesthetics, its ornamentation being produced with small tools and gilt and another one which is Oriental, in Persian style' according to Ricard, but could be more correctly defined as Ottoman. The bindings from the last group are decorated with a central mandorla and eventually also with four corner pieces, these five components being stamped with plates. This technique, originating in the Eastern part of the Islamic world, was

1 Abū al-‘Abbās Aḥmad b. Muḥammad al-Sufyānī, Șinā‘a tasfir al-kutub wa-hill al-dhahab, ed. Ricard 1925 [1st ed. 1919], and its translation in Levey 1962.

2 Ricard 1933, 110.

2 Open Access. (C) 2021 Nuria de Castilla, François Déroche, published by De Gruyter. (ब) BY-NC-ND This work is licensed under the Creative Commons Attribution-NonCommercial-NoDerivatives 4.0 International License. https://doi.org/10.1515/9783110753301-021 
met with a tremendous success as it allowed for a quick and sophisticated decoration of the binding boards. It also reduced the variations as the same plate could be used for various bindings and result in almost exactly the same pattern stamped on each of them, which is not the case with the small tools.

Variations were nevertheless possible with this technique, but they were of another nature: a contrast between the stamped decoration and the rest of the board can be obtained by stamping the plate(s) on pieces of leather or paper of another colour, by extensive gilding and painting, etc. During the Saadian period, Moroccan binders started to use these new techniques and aesthetics that were apparently well received by their customers. ${ }^{3}$ In spite of this success, there may have been either some local reluctance to import wholesale the Ottoman fashion or the plates imported from Constantinople may have been too expensive for local craftsmen. Nonetheless, local imitations of the mandorla plates were soon available, engraved with patterns that do not exactly copy the very stable Ottoman repertory but reinterpret these compositions. ${ }^{4}$ In general, the plates gradually superseded the traditional bindings decorated with small tools that, in order to produce a specific ornament, had to be stamped many times in combination.

\section{Small tooling in Moroccan bindings in El Escorial collection}

The link between the binding and the manuscript it covers has to be examined with caution. In the El Escorial collection, many bindings are no longer in their original condition. In many instances, binders working for the library removed the decorated leather covering from the old boards that were then discarded and they pasted it over new boards; in this process, they may have damaged the edges of the original binding - if they were not already damaged when this restoration was carried out. It might even be possible that, in this process, the leather covering of a manuscript was glued on the boards of another one. However, the rather high number of bindings involved, some of them still very close to their pristine condition, provides us with a safeguard in our discussion of these bindings.

3 De Castilla 2019.

4 De Castilla 2019, esp. 103-106. 


\subsection{The corners and the frame}

This older tradition of Islamic bindings used small tooling for ornaments that were either central ${ }^{5}$ or covering the whole surface of the field. ${ }^{6}$ The latter version was first rectangular, but from the twelfth century on, ${ }^{7}$ binders started to prefer octagonal fields. Instead of drawing a rectangular frame corresponding with the shape of the book, they started leaving out small triangles in each of the corners, either defined by fillets and/or stamps or by stamping a triangular shape which would eventually develop later into a corner piece (Fig. 1). A number of bindings in the Real Biblioteca de San Lorenzo de El Escorial collection (hereafter: RBME) attracted our attention because they formally stand apart by the structure of their decoration from this well-established tradition of Islamic bindings.

Fifty-three examples of this specific frame are kept in the El Escorial collection. ${ }^{8}$ Their connection with the Western Islamic world is clear since only five of these bindings cover a copy written by an Eastern hand. ${ }^{9}$ The three colophons containing an indication about the place of copy suggest that they could have been prepared in Fez. ${ }^{10}$ The origin of the library itself, in any case, supports the hypothesis that the bindings are mostly - if not all - Moroccan.

The wide frames of these bindings are drawn by three, sometimes four fillets or groups of fillets almost equally separated from each other by a large space (Fig. 2a). In order to distinguish their respective positions, we will give them a number from the inside of the frame to its outside: the fillet surrounding the field itself will therefore carry the number 1,2 being attributed to that of the middle and 3 to the next one that is usually the closest to the edges of the board and 4 to the last one (when discernible). ${ }^{11}$

5 Weisweiler 1962, 46-57, types 17 to 110 (also Déroche et al. 2005, 294-296 and figs 91-93).

6 Weisweiler 1962, 41-46, types 1 to 16.

7 Weisweiler 1962, fig. 30 (manuscript dated 1197), 37 (dated 1205) and 38 (dated 1099). The dates are indicative since the relationship between the binding and the block of quires needs to be assessed.

8 On the binding of RBME 1830 is a frame which is very close to this model, but has only two fillets; conversely, the frame of RBME 986 has four fillets.

9 Among the bindings that will be discussed below, RBME 658, 1076 (copy dated 1514), 1099 (copy dated 1525), 1211 (copy dated 1479) and 1619 (copy dated 1536).

10 RBME 248, 933 and 996.

11 The outermost fillets may have disappeared during the process of restoration described below. 
For the reason alluded to above, it is not always completely clear whether all the components of the frame have been preserved since in the process of removing the leather from the original board, the fillet closest to the edges may have been lost. However, a few complete or better preserved bindings show that, at least in some instances, a fourth fillet running close to the edges was part of the frame. This is for instance the case of RBME 986 or RBME 1149. However, the three fillets previously described are a constant component in this group of bindings, along with triangular interlace ornaments set in each corner of the board.

In contradistinction to the dominant tradition of octagonal fields, the triangular corner pieces do never encroach on the rectangle drawn by fillet 1 but are always located in the part of the frame comprised between fillets 1 and 3, the space they occupy varying slightly (Fig. 2b). For this reason, the field is rectangular. A few more refined bindings additionally include a line of S-shaped tooling surrounding the frame. As for the corner pieces, they are all triangular as stated previously, but two situations can be defined. In one case, the triangular piece of interlace is not in contact with the rectangle defining the field and drawn by fillet 1 . It is therefore inserted between fillets 2 and 3 . In the second type of corner piece, on the other hand, the interlace is in contact with fillet 1 at the angle. In the majority of cases, it is comprised between the two external fillets (that is to say 1 and 3), but there are exceptions where the triangular piece of interlace is found between fillets 1 and 2. An additional decoration is sometimes associated with the corner piece: a tool has been stamped in the corner, either within the field or in a small square drawn by the extension of fillet 1 until it reached fillet 2 .

\subsection{The central ornament}

The decoration of the central ornaments is highly coherent. They are constituted by an interlace pattern which can take various forms: circles, squares standing on the tip as well as various shapes related to the aforementioned ones. These compositions are also found in association with other types of frames on the bindings of the collection. As a first step in the study of this bookbinding tradition, we shall focus here on the bindings with the type of frame described previously when it is associated with ornaments related to a square on its tip/diamond, leaving therefore aside the bindings with a circular central decoration.

Among the thirty-nine items that we shall discuss now, we shall concentrate on twenty-four bindings that are associated with manuscripts dated from 
1198 to 1579 , four of them being written in an Oriental script. Ten items are dated to the sixteenth century, but it should be noted that eight of them predate the middle of that century. ${ }^{12}$ The most recent item is dated 1579 and seems to be the original binding of the manuscript. ${ }^{13}$ Six copies were produced in the fifteenth, five in the fourteenth, two in the thirteenth and one in the twelfth century.

The interlace is actually a very old component of the binding decorations since it appears on Qur'anic bindings of the ninth century, with a characteristic decoration of 'caterpillar'. ${ }^{14}$ With the passing of time, the tools used to stamp this decoration have evolved. In the earliest examples, a tool with two or four teeth was used to produce the pattern little by little by stamping the tool repeatedly, the interlace effect being enhanced by the impression of fillets on both sides of the sequence of impressions. ${ }^{15}$ Later, the size of components of the interlace pattern was reduced and smaller tools were required: the binders usually combine two tools when stamping this kind of composition, a segment and a quarter of circle with two fillets framing a series of short dashes - either perpendicular to the fillets or oblique. ${ }^{16}$ In this way, they were able to complete the compositions more quickly (Fig. 2b). All the Moroccan binders who prepared the bindings under examination used both tools. As it is generally the case in the Muslim world in Medieval times, they had only a limited toolkit at hand: besides the two interlace tools already mentioned, the examination of the bindings under discussion shows that they employed between one and three additional tools for the bindings of this group, essentially punches and less frequently rosettes or rosette-like and palmette-shaped tools. On three bindings only, other shapes do appear.

\subsubsection{Type A}

A first type of central ornaments stamped on the bindings (Type A) is a square standing on its tip (Fig. 3a). The loops of the interlace delimit spaces where the binder eventually stamped larger circular tools like rosettes or related shapes.

12 Seven manuscripts from the first half of the sixteenth century, two (RBME 964 and 1077) from its second half.

13 RBME 1077.

14 Marçais and Poinssot 1948; Déroche 1986; Dreibholz 1997.

15 Marçais and Poinssot 1948, 322-324 and fig. 54; Dreibholz 1997, 17.

16 An exception with parallel fillets engraved on the segment appears on the binding RBME 760 (a copy dated 1198). 
These spaces are located on the vertical and horizontal axes: at their intersection, a space is located at the centre of the ornament, the others being arranged above it, on both sides and below. In some cases, the central ornament does not include such spaces: the loops of the interlace run very close to each other and completely cover the square. Smaller punches have been stamped in the loops of the interlace and on the outside of the square. Single or double fillets starting from the tips of the square have sometimes been drawn by the binders on the horizontal and vertical axes of the board. Type $\mathrm{A}$ is the most commonly found in our sample, probably owing to the easiness of its execution. Eleven items are found, eight of them associated with manuscripts dated from 1209 to $1520 .^{17}$

A first variant of this central ornament (Type A.a) resembles a shape frequently used by Muslim bookbinders, that of the eight-pointed star. On the bindings of the El Escorial collection, this variant of Type A relies on a slight modification of the sides of the square, interrupted in their middle by an additional loop of the interlace (Fig. 3b). Segments of fillets radiate usually from the tip of the eight outer loops, corresponding to the axes and their bisectors, towards the sides of the field. As in the simpler Type A ornaments, the loops of the interlace may delimit five spaces within the figure: sometimes a rosette or a circular tool has been stamped there, sometimes these spaces remained blank. Punches have been stamped in the loops of the interlace as well as on the outside of the ornament. This composition was almost as successful as the previous one: ten items are found in the collection, seven being associated with dated manuscripts, from 1315 to $1565 .{ }^{18}$ Both Type A and Type A.a involve the stamping of rosettes, a tool that is not used on the other bindings that will be discussed now.

A second variant of this central ornament (Type A.b) keeps the general outline of Type A, but the interlace does not include blank spaces (Fig. 3c). Instead,

17 Unless otherwise stated, the manuscripts are written in Maghrebi script. RBME 658 (copy in Oriental script), 1003 (copy dated 1438), 1033, 1035 (copy dated 1520), 1122 (copy dated 1518), 1191 (copy dated 1209), 1211 (copy in Oriental script, dated 1479), 1246 (copy dated 1303), 1514 (copy dated 1234, binding perhaps taken from another manuscript), 1863 (copy dated 1499) and 1867. RBME 658, 1003, 1033, 1035, 1122, 1192, 1211, 1514 and 1867 have been restored in El Escorial.

18 RBME 276, 384 (copy dated 1508), 632 (copy dated 1324), 933 (binding perhaps taken from another manuscript), 964 (copy dated 1565), 1067 (copy dated 1315; binding perhaps taken from another manuscript), 1076 (copy in Oriental script, dated 1514; binding taken from another manuscript?), 1262, 1322 (copy dated 1543), 1465 (copy dated 1455). RBME 1322 has actually an eight-pointed star outline. RBME 933, 1067, 1076, 1262, 1322, 1465 have been restored in El Escorial. 
two parallel segments of the interlace tool have been stamped on the vertical and the horizontal axes of the square on each side of its centre; they create a cross-like shape, with punches stamped in the loops of the interlace. In one case, a palmette tool has been stamped at the four tips of the square. ${ }^{19} \mathrm{~A}$ binding offers a slightly more complex version of this pattern, perhaps derived from Type A.a since an extra-loop is found in the centre of each side. ${ }^{20}$ Various parallel segments, instead of two stamped on the vertical and horizontal axes, interrupt the interlace; as in Type A.a ornaments, short fillets radiate from the tip of the eight external loops along the axes and their bisectors towards the sides of the field. Rosette stamps are not used on these bindings. Five bindings have been decorated in this way, two of them being associated with manuscripts dated 1525 and $1579 .^{21}$

\subsubsection{Type B}

The second type of central decoration (Type B) associated with the three fillets frame is smaller than the first one. The shape of the square standing on the tip has been preserved and the interlace is composed by the combination of what we would define as a square with a loop at each corner and a cruciform shape that has a long history in Islamic bindings' central ornaments (Fig. 4a). A circular stamp has been sometimes stamped in the centre of Type B compositions. In almost all examples found in the El Escorial collection, punches have been stamped in the loops of the interlace as well as on the outside of the square. Seven items were found in the collection, four of them with dated manuscripts copied between 1396 and $1507 .^{22}$

As is the case of Type A, there is a variant we called Type B.a. It would be actually more accurate to speak of variants that keep the idea of a small interlace central ornament, but vary its composition. In three cases, it terminates on the horizontal and vertical axes by a heart-like shape (Fig. 4b). ${ }^{23}$ The other two

19 RBME 1099.

20 RBME 1077.

21 RBME 979 (binding perhaps taken from another manuscript), 999, 1016, 1077 (copy dated 1579) and 1099 (copy in Oriental script, dated 1525). RBME 979, 999, 1016 and 1099 have been restored in El Escorial.

22 RBME 650 (copy dated 1396; binding perhaps taken from another manuscript), 654, 1091 (copy dated 1397), 1149 (copy dated 1507), 1150 (copy dated 1491), 1864 and 1869 (binding perhaps taken from another manuscript).

23 RBME 760 (copy dated 1525) and 1358; RBME 1830 (see n. 8) has the same central ornament. 
examples of this group do not clearly follow the same pattern; punches have been stamped in the loops of the interlace. ${ }^{24}$

A single binding with a three fillets frame does not exhibit a central ornament related to Type A and B or to their variants (and not to the circular compositions either). ${ }^{25}$ Interlace tools similar to those of the bindings previously described have been used to stamp a knot of Solomon into the leather - in association with punches.

The techniques used by Moroccan binders who produced these bindings can also be defined more precisely. Due to the scarcity of descriptions of the tools, we shall rely on the groundbreaking study by Georges Marçais and Louis Poinssot (MP). ${ }^{26}$ As was stated before, only a handful of tools were available in each workshop. The two interlace tools, segment and quarter of circle, were ubiquitous: all the workshops used them. They may vary in length or in the way the element between the two outer fillets is treated. It is mostly made of short dashes perpendicular or slightly oblique (Figs $2 b, 5 a$ and $5 b$ ), but the segment tool sometimes consists of parallel fillets. The punches were also found everywhere, MP 57c being the most popular (22 cases; Fig. 5c). The larger punches similar to MP $57 \mathrm{f}$ are either used alone (3 cases; Fig. 5d) or in combination with another kind of punch (4 cases). ${ }^{27}$ Rosettes and circular tools were also commonly used by the binders producing central ornaments Type A and A.a (Figs $5 \mathrm{~h}$ and 5f); in addition, they were used in the corners of the frame (see for instance Fig. 3a). Next to a classical rosette shape ( 9 cases) which can be compared to MP $63 \mathrm{a}-\mathrm{d},{ }^{28}$ there is a circular stamp with a central dot surrounded by other dots, also associated with Types A and A.a (3 cases; Fig. 5g). Less frequently, a palmette close to MP 64h was stamped in the corners of the frame, but it is also found at the tip of the central ornament of binding RBME 1099 (Fig. 5e). It appears mostly on bindings of Types A.a and A.b (6 cases), once with Type B. A few bindings were stamped with heated tools: this is probably the case of manuscripts RBME 999 or 1099. Gilding when present is always very limited: the three examples found in our corpus are all restricted to punches, mostly in the central ornament. ${ }^{29}$

24 RBME 1063 and 1097 (copy dated 1468; binding perhaps taken from another manuscript).

25 RBME 1619 (copy in Oriental script dated 1536).

26 Marçais and Poinssot 1948. We refer to the drawings on figs 54 to 66: MP 64h refers to fig. 64, item $h$ in Marçais and Poinssot's study. The dimensions of the tools are not considered here. For descriptions, see also Weisweiler 1962, 61-78.

27 Compare with Weisweiler 1962, 76, stamp 93.

28 Compare with Weisweiler 1962, 74, stamp 80.

29 RBME 632, 1003 and 1322. 


\section{Headbands}

Eight original headbands have been preserved: two patterns appear more often, one with parallel lines, the other one in a ' $\mathrm{W}$ ' shape, and the association of red and yellow threads is the prefered one, before blue and white; however, the ' $W$ ' pattern is dominant when one takes into consideration the corpus of fifty-three bindings with three fillets frame (10 instances). As stated previously, in most of the cases, the original lining of the inner board has been replaced in the course of the restauration. However, we found among the dated manuscripts of this group of bindings seven linings which may be original: in one case, it is a yellow paper, but fabric and leather are more numerous (three instances each). When taking into account the fifty-three bindings of our corpus, leather is better represented among the ten original linings with five instances; fabric has been used four times.

\section{Conclusion}

The relationship between the binding and the volume it protects has to be approached with caution. Bindings can be changed and this has apparently happened after the manuscripts reached the El Escorial Library: as mentioned previously, the binders/restorers replaced original bindings that were in a bad state by local ones, with the El Escorial coat of arms, or removed the old leather covering and pasted it on top of new boards. In that case, it seems that they may have used in a few cases coverings that were not originally connected with the manuscript they are associated with now. ${ }^{30}$ However, the number of items in the corpus is sufficient to approach the two fundamental questions that arise when studying bindings, that of their place of production and that of their date, without risking to err considerably in answering both questions. The El Escorial collection is particularly important in this regard since it mainly houses the manuscripts of Mulāy Zaydān (r. 1603-1627) that were captured by Spain in 1612. With the exception of the manuscripts destroyed by a fire in the end of the seventeenth century and those drastically rebound between the seventeenth and nineteenth centuries, the manuscripts are as close as possible to their state in the early seventeenth century. The library amounts to a 'time capsule', which makes an answer to the two questions easier. The first question is the simplest

30 See for instance RBME 650 or 1097. In our sample, eight manuscripts are in that case. 
one: within the group of twenty-four dated copies with both the three fillets frame and the square central ornament, only three are written by an Oriental hand, the rest being all Maghrebi; if we take into account the corpus of fiftythree bindings with the same kind of frame, irrespective of their central ornament, the Oriental copies are only five. We can conclude that the bindings with the three fillets frame were produced in the Western part of the Islamic world, presumably in Morocco.

The three dated Eastern copies with a binding with the frame described previously (Fig. 2a) were completed between 1479 and $1525 .{ }^{31}$ As for the dated Maghrebi copies, only two of them are later than the middle of the sixteenth century $;^{32}$ eight were produced in the first half of that century, ${ }^{33}$ slightly more than those dated to the fifteenth century (one from its first half, ${ }^{34}$ five from the second one $)^{35}$. We find then five fourteenth century copies, ${ }^{36}$ but only two from the thirteenth ${ }^{37}$ and one with a manuscript dated to the end of the twelfth century. ${ }^{38}$ However, the date of completion of the oldest copies is not of much use as it is highly probable that their present binding is the result of a replacement, the date of which is difficult to ascertain. In some cases, the similarities between an old binding and a more recent one suggest that the latter provides a clue for the dating: for instance, a copy dated 1315 (RBME 1067) was probably bound in the same workshop as another one prepared for a manuscript completed in 1514 (RBME 1076). The dates of the copies produced in the Eastern part of the Islamic world support the general orientation of the group of bindings associated with Maghrebi manuscripts, which invites to conclude that the period of production of these bindings extends from the late fourteenth century to the end of the sixteenth century, central ornaments of Type B and B.a being perhaps earlier

31 RBME 1076 (dated 1514), 1099 (dated 1525) and 1211 (dated 1479). RBME 1619 (dated 1536), also written in an Oriental hand, is not included in the present study since the central ornament of its boards is of another nature. These manuscripts as well as RBME 658 do not bear any trace suggesting that they were still in the Eastern part of the Islamic world at a later date. RBME 1619 bears a note dated to the same year as the transcription.

32 RBME 964 (1565) and 1077 (dated 1579).

33 RBME 384 (1508), 1035 (1530), 1076 (1514), 1099 (1525), 1122 (1518), 1149 (1507), 1322 (1543) and 1619 (1536).

34 RBME 1003 (1438).

35 RBME 1097 (1468), 1150 (1491), 1211 (1479), 1465 (1455) and 1863 (1499).

36 RBME 632 (1324), 650 (1396), 1067 (1315), 1091 (1397) and 1246 (1303).

37 RBME 1191 (1209) and 1514 (1234).

38 RBME 760 (1198). 
than Type A and its variants: the dates of the former range from 1396 to $1507,{ }^{39}$ whereas the latter include more material from the sixteenth century. ${ }^{40}$ Looking at the larger group of forty-four dated manuscripts with a binding with interlace design related to the three fillets frame group, the fifteenth and sixteenth centuries also represent the bulk of this production: twenty-five items are associated with copies completed between 1451 and the end of the sixteenth century (the latest item is dated 1584). The dates also suggest that the second part of the sixteenth century was a period of decline for this kind of decoration based on the interlace in front of the growing success of the new style imported from the Ottoman Empire. The numbers are clear: in the collection, twelve manuscripts in Maghrebi script from the last quarter of the sixteenth century have a binding alla turca against a meagre four in the 'traditional' style. ${ }^{41}$ The situation is almost reversed in the preceding quarter of this century, with respectively three of the former against twelve of the latter.

It could be possible to argue that the bindings of the manuscripts examined here were made when they were incorporated into the Saadian library. It should however be noted that some of the manuscripts discussed here bear witness of the fact that they were not yet in the Saadian library at a comparatively advanced date in the sixteenth century, which casts doubt on this possibility. On the other hand, the diversity of tools and craftsmanship, in spite of the common repertory shared by these bindings, would hardly support the idea that they were made for the sultan's library at about the same time and by the same workshop - or by a limited number of binders.

Moreover, a few bindings found in the collection show that the interlace decoration could also be used for more elaborate bindings than most of those which have been examined here. One of the best examples is the RBME $248 .{ }^{42}$ The study of this manuscript completed in Fez on 17 Safar 969/27 October 1561 for a princely patron, confirms that traditional Maghrebi techniques were still alive in the third quarter of the sixteenth century and that the type with the three fillets frame was used in upper end workshops. Its binding, as that of RBME 47, bears testimony of the skill of some binder. However, towards the same date, other Maghrebi copies were already covered by bindings decorated

39 We exclude RBME 760 (dated 1198); RBME 650 and 1091 are respectively dated 1396 and 1397, and the copy of RBME 1149 was completed in 1507.

40 Nine bindings in total (RBME 384, 964, 1035, 1076, 1077, 1099, 1122, 1322 and 1863).

41 Taking into account all the Moroccan bindings with the three fillets frame, irrespective of the central ornament.

42 See Déroche 2014; Déroche 2019, 181-190. 
in an almost identical way as those produced in Ottoman binderies. The data at our disposal are scarce and contradictory. The 'old style', if we may call it thus, does not seem to be a matter of geography: as indicated at the beginning, three bindings in the larger group of interlace decoration were prepared in Fez, but RBME 47 seems to have been bound in Marrakesh. Economics may have played a role: the small tools were locally produced, whereas the Ottoman plates had to be imported and were likely more expensive. On the other hand, high quality bindings were prepared with the traditional set of tools and local imitations of the plates soon became available. ${ }^{43}$ Tastes also were important: some patrons probably preferred the 'old style' while others were favouring the Ottoman aesthetics.

If our dating of the group of bindings with three fillets frame and a square related central ornament is correct, the copies in Oriental script may have been bound for the first time in Morocco. As they were produced about a century before Mulāy Zaydān's library was seized, with the exception of RBME 1211, it can be doubted that their bindings were renewed during this comparatively short period of time. This might imply that they were imported without a proper binding, an interesting information about the book trade between the Eastern part of the Mediterranean and Morocco.

This group of bindings is crucial for our reconstruction of bookbinding history in Morocco between the fifteenth and early seventeenth century. It is a witness of the survival of techniques and aesthetics in Morocco until late into the sixteenth century that were rooted in a long tradition. As stated by alSufyānī, Moroccan binders were still, in his time, catering to the tastes of book owners who liked the traditional Maghrebi style. They were also working for those who preferred the Ottoman tastes and techniques. The study of a larger corpus of Moroccan bindings, both decorated with small tools and with plates, will allow us to follow the changes during the Saadian period and their chronology. It might also provide clues about regional peculiarities and the sociology of Moroccan book owners in Saadian times. And the sheer number of examples in a collection with a specific provenance may also lead to the identification of workshops active in the sixteenth and early seventeenth centuries.

43 De Castilla 2019, esp. 103-106. 


\section{Acknowledgements}

The research leading to these results has received funding from the European Research Council under the European Union Funding for Research and Innovation (Horizon 2020) ERC Grant Agreement number 670628, 'Saadian Intellectual and Cultural Life' (SICLE, 2016-2021). The authors are particularly grateful to the Director of the Library of the San Lorenzo de El Escorial, P. José Luis del Valle, for his help during the research leading to these results.

\section{References}

de Castilla, Nuria (2019), 'Maghrebi bindings in Ottoman dress. About techniques and changes of taste in Saadian Morocco', Turcica, 50: 89-113.

Déroche, François (1986), 'Quelques reliures médiévales de provenance damascaine', Revue des études islamiques, 54: 85-99.

Déroche, François (2014), 'Des miscellanées princières d'époque saadienne. Le manuscrit 248 de la bibliothèque de San Lorenzo de l'Escorial', in Nicholas de Lange and Judith OlszowySchlanger (eds), Manuscrits hébreux et arabes: Mélanges en l'honneur de Colette Sirat (Bibliologia, 38), Turnhout: Brepols, 163-174.

Déroche, François (2019), 'The prince and the scholar: A study of two multiple-text manuscripts from fifteenth and sixteenth centuries Morocco', in Alessandro Bausi, Michael Friedrich and Marilena Maniaci (eds), The Emergence of Multiple-Text Manuscripts (Studies in Manuscript Cultures, 17), Berlin: De Gruyter, 165-191.

Déroche, François et al. (2005), Islamic codicology, an introduction to the study of manuscripts in Arabic script, London: Al-Furqān Islamic Heritage Foundation.

Dreibholz, Ursula (1997), 'Some aspects of early Islamic bookbindings from the Great Mosque of Sana'a, Yemen', in François Déroche and Francis Richard (eds), Scribes et manuscrits du Moyen Orient, Paris: Bibliothèque Nationale, 16-34.

Levey, Martin (1962), Mediaeval Arabic Bookmaking and its Relation to Early Chemistry and Pharmacology $=$ Transactions of the American Philosophical Society, N.S., 52/4.

Marçais, Georges and Louis Poinssot (1948), Objets kairouanais, IXe au XIII $I^{e}$ siècle. Reliures, verreries, cuivres et bronzes, bijoux, vol. 1, Tunis: Tournier / Paris: Klincksieck.

Ricard, Prosper (ed.) (1925), Abū al-'Abbās Aḥmad b. Muḥammad al-Sufyānī, Art de la reliure et de la dorure, 2nd edn, Paris: Paul Geuthner.

Ricard, Prosper (1933), 'Reliures marocaines du XIII' siècle. Notes sur des spécimens d'époque et de tradition almohade', Hespéris, 17: 109-127.

Weisweiler, Max (1962), Der islamische Bucheinband des Mittelalters nach Handschriften aus deutschen, holländischen und türkischen Bibliotheken, Wiesbaden: Otto Harrassowitz. 


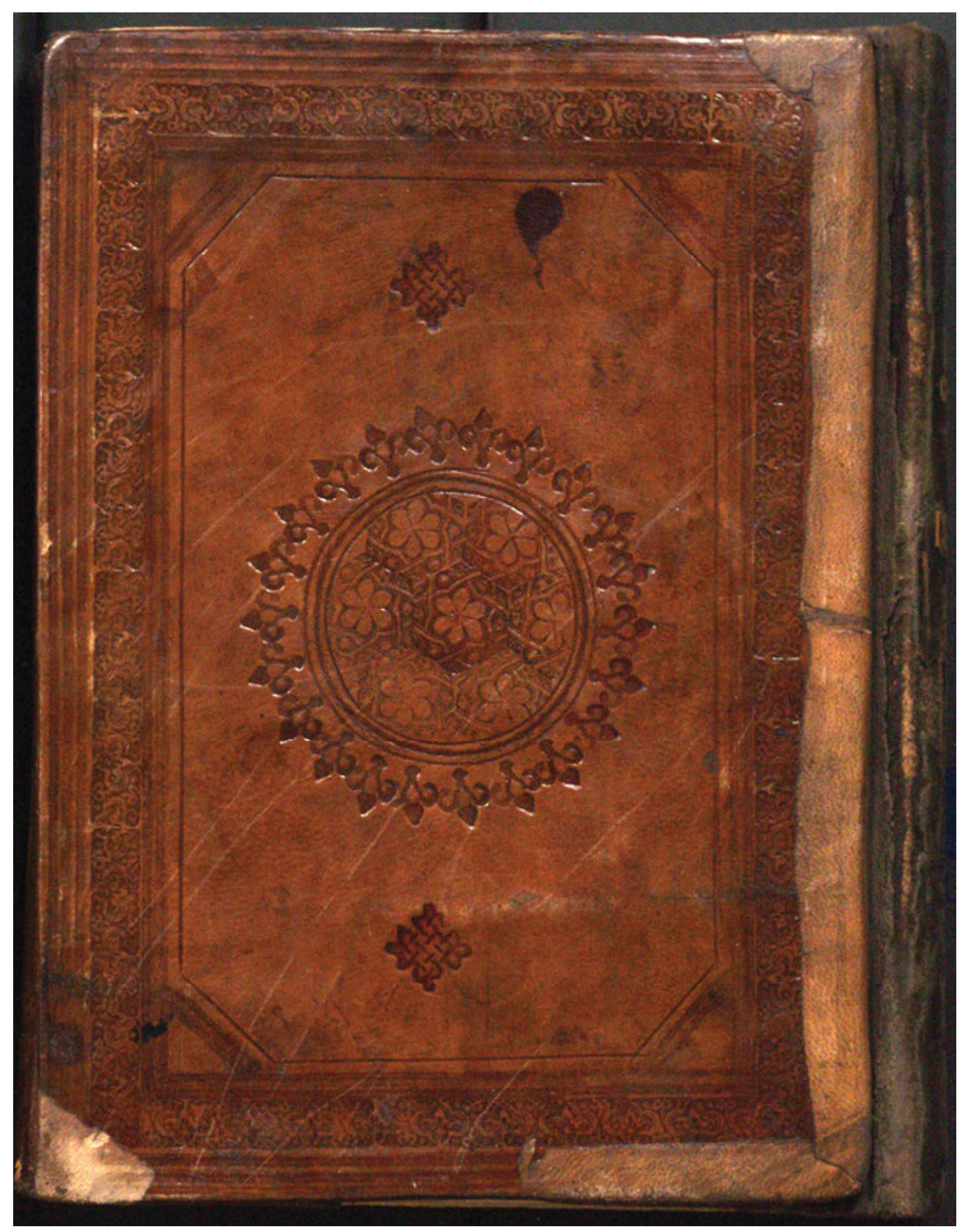

Fig. 1: Binding, Morocco, end of the 15th-16th c. RBME 1540 (copied in 1469). CReal Biblioteca del Monasterio de San Lorenzo de El Escorial. 


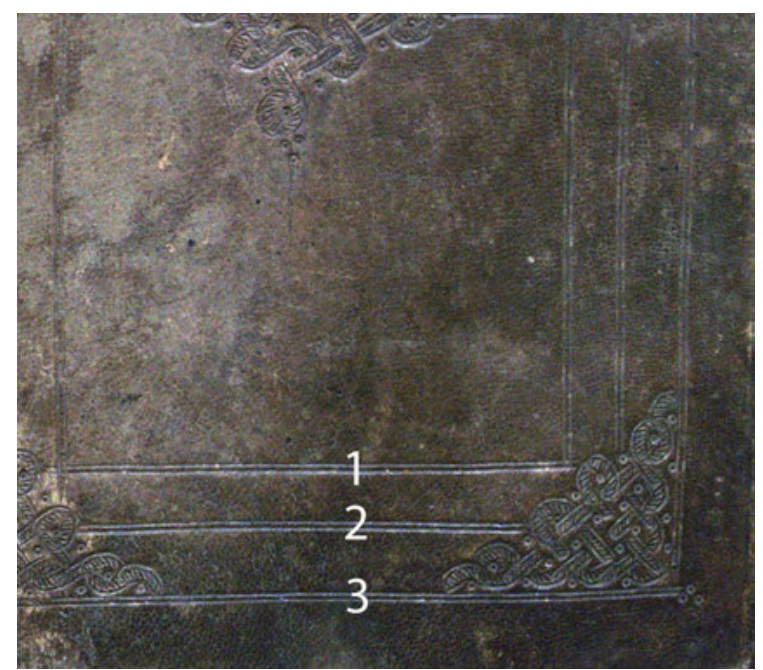

Fig. 2a: Binding, detail of the frame (with the fillets number indicated) and the cornerpiece, Morocco, 16th c. RBME 1149 (copied in 1507).

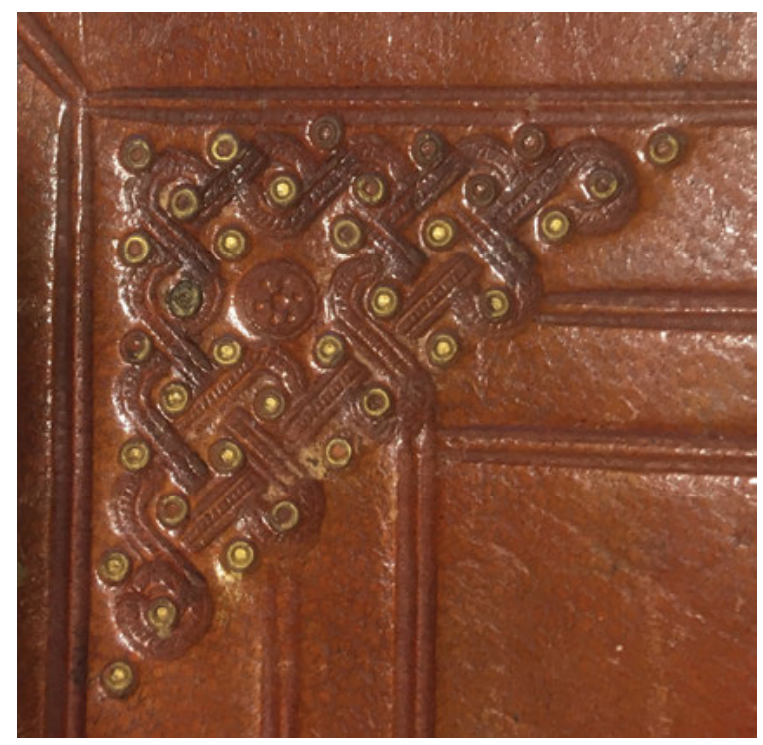

Fig. 2b Binding, detail of the cornerpiece with the two interlace tools, Morocco, second half of the 16th c. RBME 248 (copied in 1561).

Figs 2a-b @ Real Biblioteca del Monasterio de San Lorenzo de El Escorial. 


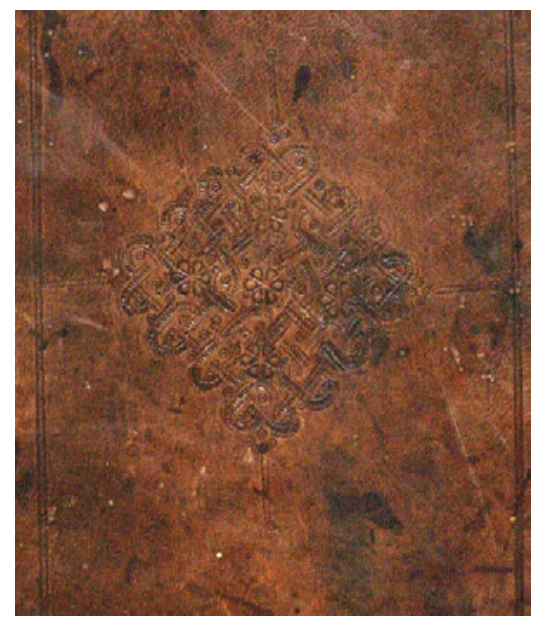

Fig. 3a: Binding with central ornament Type A, Morocco, 15th-16th c., RBME 1191 (copied in 1209).

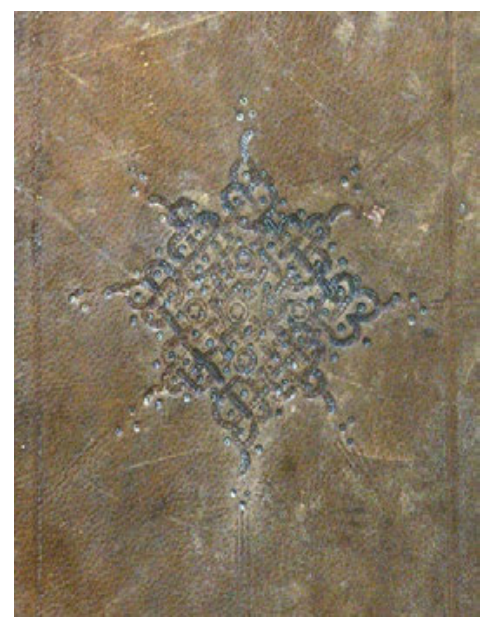

Fig. 3b: Binding with central ornament Type A.a, Morocco, second half of the 16th c. RBME 964 (copied in 1565).

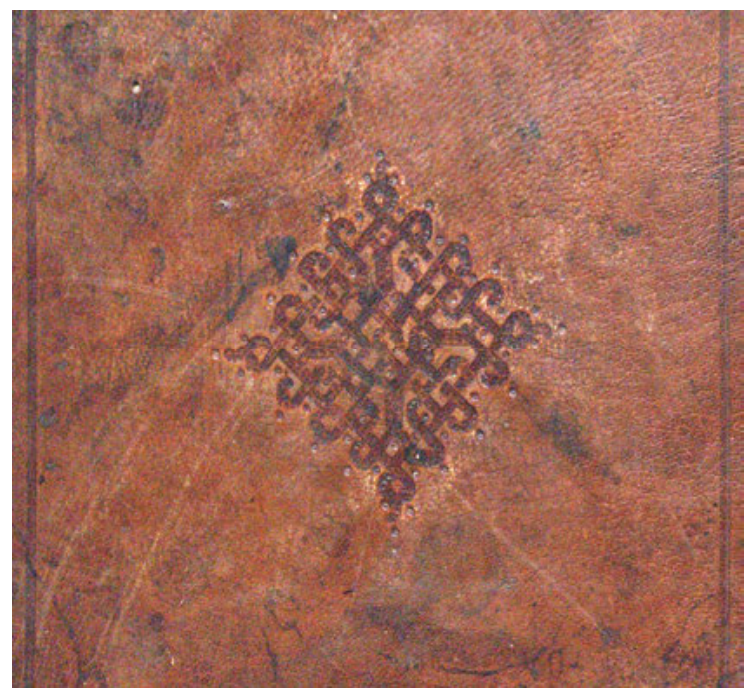

Fig. 3c: Binding with central ornament Type A.b, Morocco, 16th c. RBME 1016 (probably copied in the 16 th c.).

Figs 3a-c @ Real Biblioteca del Monasterio de San Lorenzo de El Escorial. 


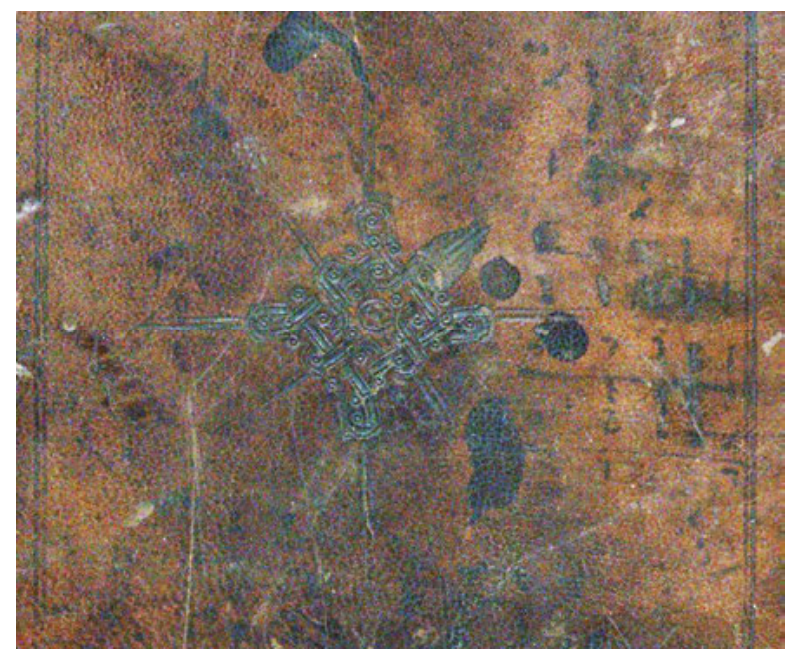

Fig. 4a: Binding with central ornament Type B, Morocco, 16th c. RBME 654 (copied in the 16th c.).

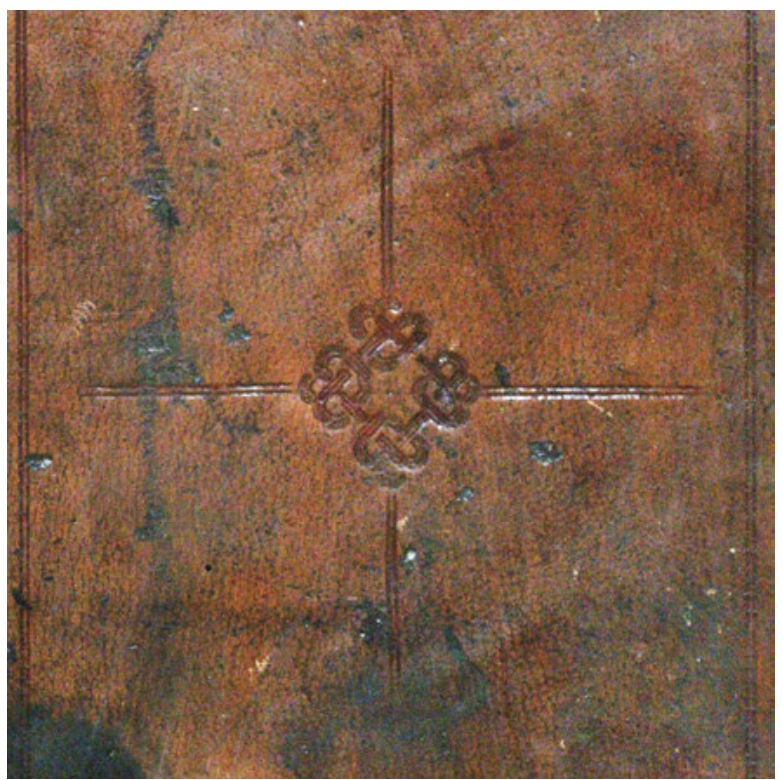

Fig. 4b: Binding with central ornament Type B.a, Morocco, end of the 15th-16th c. RBME 1358 (copied at the end of the 15th-16th c.).

Figs 4a-b @ Real Biblioteca del Monasterio de San Lorenzo de El Escorial. 
a

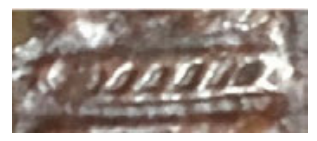

\section{$\| I I I I I I I /$}

C
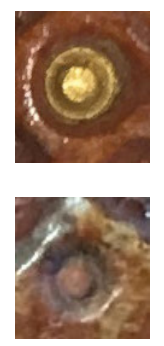

(2)

f

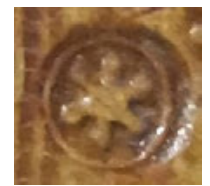

$\mathrm{h}$

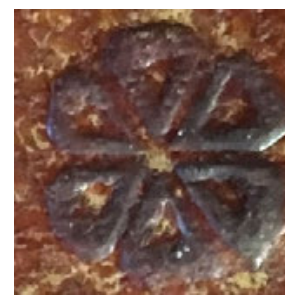

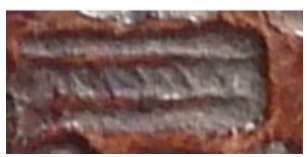

d
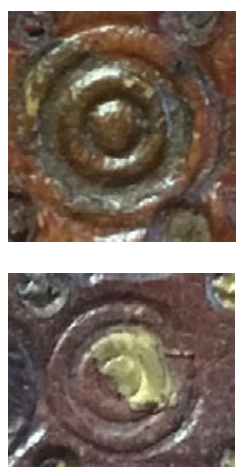

b
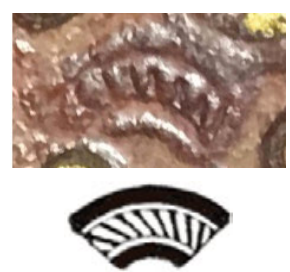

e
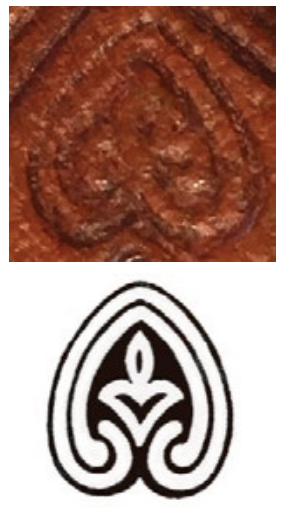

g
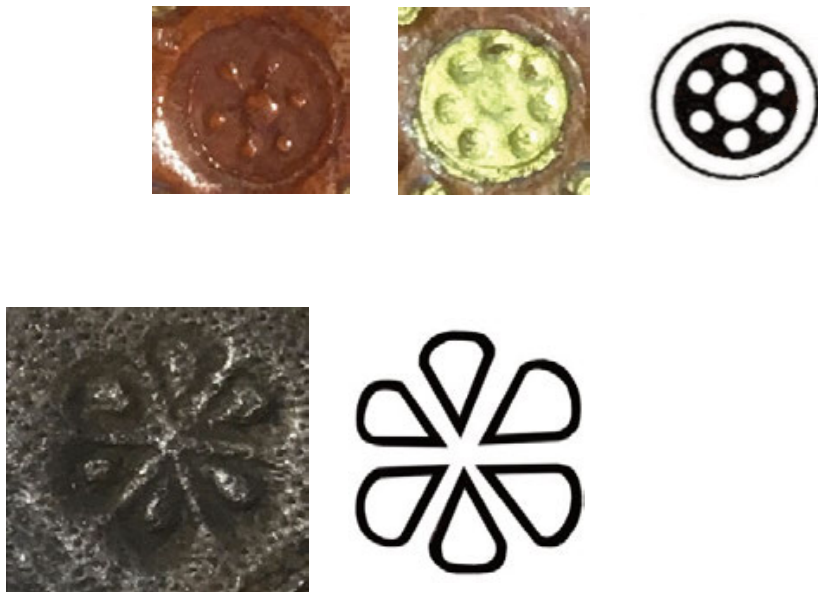

Fig. 5: Stamps. Images published in Marçais and Poinssot, 1948: a = Fig. 54b; b = Fig. 55d; c = Fig. 57Fe; e= Fig. 64h; g = Fig. 58m, and h= Fig. $63 \mathrm{e}$. 